\title{
Minimal access oesophagectomy; review of out come
}

\author{
KB Galketiya ${ }^{1}, V^{2}$ Pinto ${ }^{1}$ \\ ${ }^{I}$ Faculty of Medicine, University of Peradeniya, Sri Lanka
}

\begin{abstract}
Minimal access oesophagectomy may be performed by thoraco-laparoscopic or laparoscopic transhiatal techniques. Thoracoscopy gives a better visualization of intra-thorasic anatomy than trashiatal approach but has the disadvantage of making lung collapse during surgery a requirement. A comparison was done of both techniques. Surgery was completed safely by both methods. Thoracoscopy took more time and patients were electively ventilated for one day whereas transhiatal group were extubated in the immediate post operative period. Two patients of thoracoscopy group required re-intubation for lung infections and one of them died. If post operative pulmonary care is improved thoracoscopy may be the better technique as it allows more precise oncologically acceptable dissection.
\end{abstract}

Keywords - oesophagectomy, minimal access

\section{Introduction}

Oesophagectomy is the surgical treatment for resectable oesophageal carcinoma1. There is a significant morbidity and an associated mortality1,8. It may be done with a thoracotomy and a laparotomy with an intrathorasic anastomosis; two stage oesophagectomy. In three stage procedure the anastomosis is performed in the neck ${ }^{1}$.

Thoracotomy contributes significantly to the morbidity. It may lead to many respiratory complications. To minimize this transhiatal blunt oesophagectomy was introduced by Orringer; the oesophagus being mobilized through the hiatus with out vision. Even though thoracotomy is taken away there is a risk of haemorrhage and the resection may be inadequate and will not allow any lymph node clearance ${ }^{1,8}$.

Minimal access oesophagectomy allows the procedure to be done without thoracotomy and laparotomy ${ }^{1,2,3,4,5,6,7}$. This may be done in two ways.

1. Laparoscopy, thoracoscopy and neck incision

2. Laparoscopy, transhiatal minimal access mobilization of oesophagus and neck incision

\section{Objectives}

Comparison of the surgical technique used in thoraco-laparoscopic oesophagectomy and laparoscopic transhiatal oesophagectomy. 


\section{Method}

The patients undergoing oesophagectomy were performed by minimal access technique. The patients with tumours in lower end were done by transhiatal approach while others by thoraco-laparoscopically

The following data were collected

1. blood loss

2. duration of surgery

3. conversions

4. post operative out come

\section{Results}

Twenty patients underwent surgery and four were thoraco-laproscopic and sixteen transhiatal. Ten were males.

\section{Comparison of technique}

In both situations mobilization of stomach was laparoscopic with five ports. The thorasic oesophagus was mobilized by thoracoscopy in one group and via hiatus in the other group. The last stage of neck dissection was same in both groups.

The thoracoscopy was done as first stage in thoraco-laparoscopic group. Patient was placed in semi-prone position and surgery performed using three ports. Space for dissection was obtained by a capnothorax with an insufflation pressure of $8 \mathrm{mmHg}$. Prone position allows the collapsed lung to fall away from the field of dissection. Once thorasic oesophagus was mobilized patient was placed supine for laparoscopy.
In all patients a neck incision was made on left side to mobilize cervical oesophagus. Then the oesophagus was transected and a naso-gastirc tube anchored to lower end. A minilap of about $4 \mathrm{~cm}$ was made, stomach held with a Babcock grasper to pull out stomach and oesophagus. Following division of oesophagus a stomach tube was constructed and a pyloromyotomy done. The stomach tube is pulled up to neck and oesophago-gastirc anastomosis performed.

The following tables compares the time taken and blood loss for each stage.

Table 1-Thoraco-laparoscopy

Table 2-Laparoscopic transhiatal

\section{Conversions to open surgery}

In both groups a mini laparotomy was electively made to construct the stomach tube. The other alternative is to use laparoscopic stapling which may add a cost of about 50,000 to 75,000 rupees for stapler guns and reloads.

In two patients of transhiatal group it was difficult to get full mobilization of oesophagus. The mobilization was completed transhiatally by blunt dissection through laparotomy. Two patients with tumours at gastrooesophageal junction were found to unresectable and procedure abandoned.

All patients who underwent transhiatal dissection were extubated at end of procedure. In the thoraco-laparoscopy group all four patients were ventilated for twenty four hours. Two of them required re-ventilation secondary to respiratory tract infections. One of them died after two weeks with multi organ failure. 


\section{Discussion}

By performing oesophagectomy by minimal access technique its possible to do avoid large incisions. By avoiding an incision post operative pain become less which allows early mobilization. When pain is less breathing difficulties are less and respiratory complications are reduced.

To compare thoraco-laparoscopic and transhiatal approaches by the technique the former takes extra time for positioning. In addition it involves collapsing the lung. The thoracoscopy patients were electively ventilated for twenty four hours where as the trashiatal patients were extubated at end of procedure. Furthermore two patients of thoracoscopy group were reintubated due to chest infections and one died after two weeks. Transhiatal technique may be associated with a lesser incidence of post operative chest complications.

However during thoracoscopy we do not use lung collapse by blocking ventilation by double lumen endotracheal tube; a single lumen tube is used and a partial lung collapse is obtained by a capnothorax. This has proved to be an effective and easier technique ${ }^{9,10,13}$.

Further the standard positioning in thoracoscopic oesophagectomy is full prone 4,8 . However we use a semi-prone position which is proven to have many advantages over full prone position ${ }^{9,11,12}$. Thoracoscopy has the advantage of having a greater vision of all surrounding anatomy allowing a controlled and safe dissection. This technique could be used for tumours at any level whereas the transhiatal technique should be reserved for lower end tumours ${ }^{8,9}$. Thoracoscopic dissection has more potential for better lymph node dissection ${ }^{8}$. Out of the patients we operated in a complete transhiatal dissection was not possible and we had to perform a blunt dissection. The problem in thoracoscopy vision of the surrounding anatomy is limited ${ }^{9}$. The space available for instruments is also limited. In thoracoscopy to achieve complete dissection is easier as its done under direct vision with more space for dissecting instruments.

The time taken in thoracoscolaparoscopy is more mainly due to the time taken for repositioning. Blood losses are comparable.

\section{Conclusions}

Thoraco-laparoscopy and laparoscopic transhiatal techniques can be used safely for oesophagectomy. The former allows a better visualized precise anatomical dissection. However it is necessary to collapse the lung for thoracoscopy which may increase the risk for chest infections. If pre and post operative pulmonary care can be improved to minimize chest complications thoracoscopy would be the better technique as it allows a more precise oncological dissection.

Prof. KB Galketiya,

Professorial unit,

Teaching hospital, Peradeniya.

kbgalketiya@yahoo.com

Submitted by - March 2019

Accepted by - May 2019 
KB Galketiya, V Pinto - Minimal access oesophagectomy; review of out come

\section{References}

1. Joris J G Scheepers, Donald L van der Peet, Alexander A F A Veenhof, and Miguel A Cuesta Thoracoscopic resection for esophageal cancer: A review of literature J Minim Access Surg. 2007 Oct-Dec; 3(4): 149-160. doi: 10.4103/0972-9941.38909

2. Shi-ping Luh ,Hui-ping Liu Videoassisted thoracic surgery-the past, present status and the future $\mathrm{J}$ Zhejiang Univ Sci B. Feb 2006; 7(2): $118-128$

3. Galketiya KB, PintoV, SM Bandara. Thoracoscopy; beyond the key hole.The Sri lankan Journal of Surgery 2014;32(1):29-34

4. Dapri G, Himpens J, Cadière GB. Robot-assisted thoracoscopic esophagectomy with the patient in the prone position. J Laparoendosc A d v Surg Te ch A. 2006 Jun;16(3):278-85.

5. Nguyen NT, Roberts P, Follette DM, Rivers R, Wolfe BM.Thoracoscopic and laparoscopic esophagectomy for benign and malignant disease: lessons learned from 46 consecutive procedures. J Am Coll Surg 2003;197:902-13

6. Collard JM. Role of video assisted surgery in the treatment of oesophageal cancer. Ann Chir Gynaecol 1995;84: 209-14.

7. McAnena OJ, Rogers L, William NS. Right thoracoscopically assisted oesophagectomy for cancer. $\mathrm{Br} \mathrm{J}$ Surg 1994;81:236-8.

8. PalaniveluC. Minimally invasive surgery in oesophageal carcinoma- current concepts. Art of laparoscopic surgery Jaypee 2007;393

10. KB Galketiya, MVG Pinto, Minimal access esophagectomy: Review of technique. International Archives of Integrated Medicine, February 2015;2(2)1-7

11. MVG Pinto, KB Galketiya, Comparison of the use of single lung ventilation Vs both lung ventilation in Video Assisted thoracoscopy. International Journal of Scientific and Research Publications February $2015 ; 5(2)$

12. K.B.Galketiya, M..V.Pinto, A new approach for thoracoscopic posterior mediastinal procedures. Ruhuna Journal of Science 2014;(5):10-20

13. Galketiya KB, Pinto V, The influence of patient positioning to obtain adequate space for dissection in Video assisted thoracoscopic surgeries (VATS). International Journal of Scientific and Research Publications 2014;4(12)

14. V. Pinto, KB Galketiya, Insufflation pressure required for thoracoscopic surgery and its influence on respiratory and cardiovascular parameters. Sri Lankan Journal of Anaesthesiology 2014;22(2):55-58 
KB Galketiya, V Pinto - Minimal access oesophagectomy; review of out come

\section{Tables}

Table 1-Thoraco-laparoscopy

\begin{tabular}{|l|l|l|l|l|l|}
\hline & Thoracoscopy & $\begin{array}{l}\text { Turning } \\
\text { patient }\end{array}$ & Laparoscopy & Neck phase & $\begin{array}{l}\text { Minilap and } \\
\text { anastomosis }\end{array}$ \\
\hline Time (min) & $90-120$ & Average -30 & $\begin{array}{l}60-120 \\
\text { Average }-90\end{array}$ & $\begin{array}{l}30-45 \\
\text { Average }-40\end{array}$ & $\begin{array}{l}30-40 \\
\text { Average }-35\end{array}$ \\
\hline Alood loss(ml) & $<75$ & - & $<50$ & $<50$ & $<50$ \\
\hline
\end{tabular}

Table 2-Laparoscopic transhiatal

\begin{tabular}{|l|l|l|l|l|}
\hline & Laparoscopy & Transhiatal & Neck phase & $\begin{array}{l}\text { Minilap and } \\
\text { anastomosis }\end{array}$ \\
\hline Time (min) & $\begin{array}{l}70-130 \\
\text { Average }-85\end{array}$ & $\begin{array}{l}75-120 \\
\text { Average }-90\end{array}$ & $\begin{array}{l}35-45 \\
\text { Average }-40\end{array}$ & $\begin{array}{l}40-50 \\
\text { Average }-45\end{array}$ \\
\hline Blood loss $(\mathrm{ml})$ & $<50$ & Average -100 & $<50$ & $<50$ \\
\hline
\end{tabular}

